\title{
Thermographic Inspection in the Electric Industry
}

\author{
Ferenc HARASZTI \\ Óbuda University, Donát Bánki Faculty of Mechanical and Safety Engineering, Institute of Materials and \\ Manufacturing Sciences, Department of Materials Technology, Budapest, Hungary \\ haraszti.ferenc@bgk.uni-obuda.hu
}

\begin{abstract}
The traditional inspection of fittings used in the electrical industry is a cumbersome, dangerous process in terms of safety and operation. However, with the spread of thermography, these tests can be performed simpler, faster, and more safely through electrical connections. This article presents the possibilities, measurement difficulties and the advantages of thermography analysis [1-2].
\end{abstract}

Keywords: thermography, thermographic camera, electrical industry.

\section{Introduction}

There are a large number of electrical fittings in the electricity industry. Most of which utilize copper, steel, aluminium and their alloys [3-8]. Due to differences in the potential of different materials, galvanic corrosion may occur. This process can lead to failure of the joint. The increased resistance causes heat generation is shown in Figure 1. and Figure 2.

Therefore, we have used a thermal imaging procedure over the past few years. The benefits include safe and uninterrupted measurement. Previously we investigated the relationship between heat development and current.

Our measurements could only be accurate within a certain tolerance as metals can change

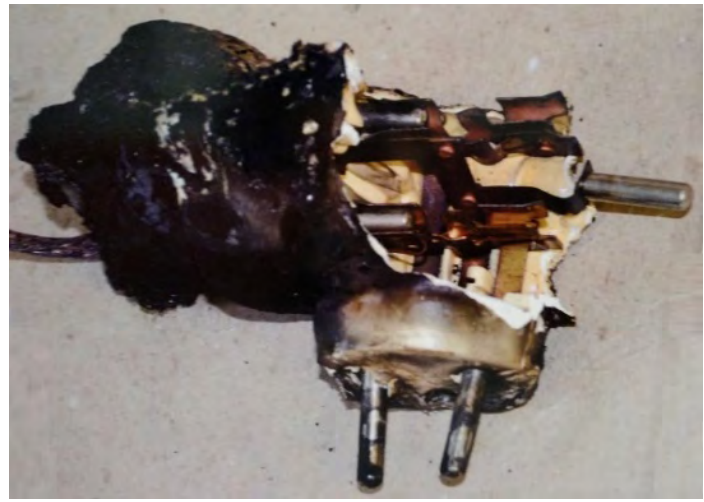

Figure 1. Galvanic corrosion affected damage their electrical resistance due to heat, which can only result in thermal evolution according to the degree of heating. In this paper, we test copper and steel used in the electrical industry. The copper-steel coupling resistance varies as a function of the temperature.

\subsection{Resistance to the temperature depen- dence}

If a metal is subjected to a strong heating effect, its resistance increases. It can be stated that the resistance generally depends on the temperature $[9,10]$. For metals, the temperature increases proportionally, with semiconductors, coal, and electrolytes proportionally decreasing. Examined at extremely high temperatures and relatively small intervals, the specific resistance $\rho$ of the

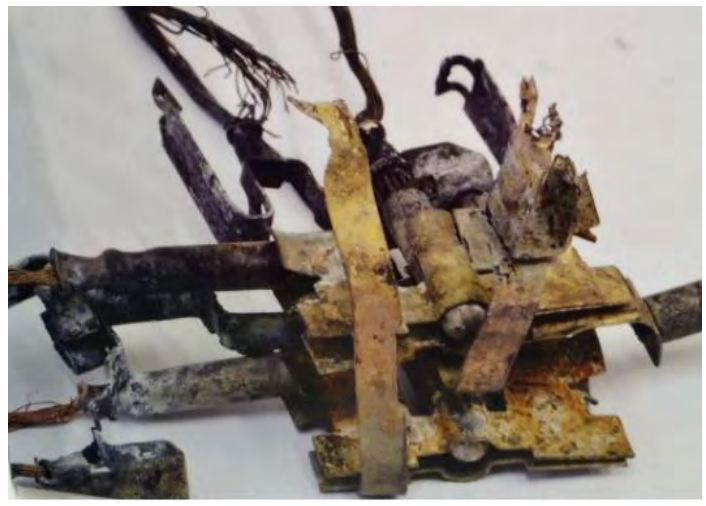

Figure 2. Galvanic corrosion affected damage 
metals in question is proportional to the temperature range tested [11].

The applied relationship (1):

$$
\frac{\rho-\rho_{0}}{\rho_{0}}=\propto\left(t-t_{0}\right)
$$

where:

$\rho=$ specific resistance $(\Omega \mathrm{m})$,

$\alpha=$ temperature coefficient $\left(1 / \mathrm{C}^{\circ}\right)$,

$t=$ temperature $\left(\mathrm{C}^{\circ}\right)$.

Instead of the specific resistance, we can use the concept of equivalent electrical resistance, and then our relationship is as follows (2):

$$
\mathrm{R}=\mathrm{R}_{20}\left(1+\mathrm{a}_{20} \cdot \Delta \mathrm{t}\right)
$$

where:

$\mathrm{R}=$ electrical resistance $(\Omega)$,

$\mathrm{R}_{20}=$ Resistance on $20 \mathrm{C}^{\circ}(\Omega)$,

$\mathrm{a}_{20}=$ Temperature factor on $20 \mathrm{C}^{\circ}\left(1 / \mathrm{C}^{\circ}\right)$.

The resistivity of the copper and steel fittings used in industry as a function of temperature is shown in the graph below (Figure 3.).

In our case, it is not necessary to extend the temperature range $\left(0-700^{\circ} \mathrm{C}\right)$, as the harmful warming of the abnormally fast electrical binder can be done in this interval.

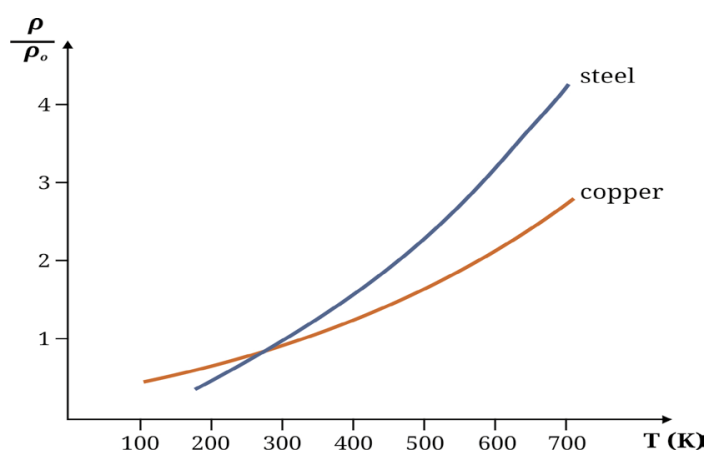

Figure 3. Resistance versus temperature [6]

\subsection{Non-contact temperature measurement}

The infrared-based temperature measurement and thermal imaging method depend on the heat radiating ability of the bodies. Temperature radiation is the process that emits electromagnetic waves due to heat movement in the material. Much of this energy can be emitted or reflected on another body and can be transmitted. If radiation arriving on the test body is absorbed without any remaining excess heat, then we are dealing with an absolutely black body.
In practice, we use the laws of physics. The infrared range of the electromagnetic spectrum emitted by the surface of the object under consideration is measured with the thermal camera and transformed into an electric signal [6-7]. The accuracy of our measurement data is mainly determined by the instrument specification itself, the medium of the object to be measured and the surface of the object to be measured. The wavelength of the light we perceive varies between 0.4 and $0.75 \mu \mathrm{m}$. The infrared range may differ from this range between 0.75 and $20 \mu \mathrm{m}$. In heat detector analysis practice, we can examine this range.

\section{Examination of electrical fittings}

Our goal is to determine the resistance of a steel-copper pair depending on the temperature. How much does it contribute to the electrical resistance of a steel-copper connection with high contact resistance with galvanic corrosion? What degree of resistance is represented by the general electrical contact used in the industry when considering only the parameters examined by warming?

On the base of the literature data, the specific resistance (and $\mathrm{R}$ resistance) is not significantly considerable about the view of the temperature. Nevertheless, it is important to know how its values develop if we are not testing it under laboratory conditions. In our case, an everyday copper rack and a steel screw are the subjects of the test (Figure 4.).

The measurement is performed in the assembled condition, tightening the screw with the correct torque. Due to the magnitude and accuracy of the resistance value, we work with a Wheatstone bridge measurement method. The applied thermal imaging camera ensures contactless temperature reading without interruption [12]. The heating of the electric joint component is supported by a precision electrical heater. The schematic diagram of the measurement is shown in Figure 5. and the setup of the measurement is shown in Figure 6 .

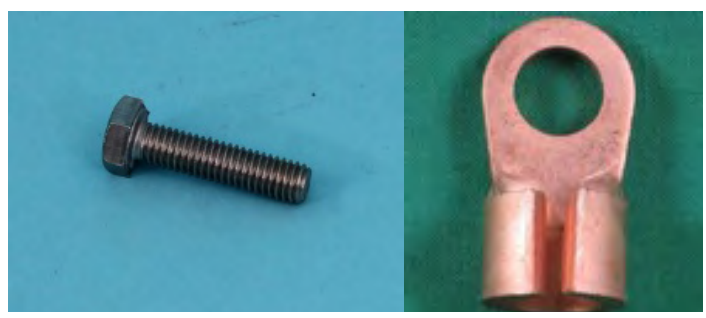

Figure 4. Fittings 


\subsection{Measurement results}

During the experiment, five series of measurements were prepared and after error calculation, the following results were obtained (Table 1.):

The resultsof resistence as a function of the temperature, shown in the next diagram (Figure 7.) .

By evaluating this, we can conclude that the course of the function is similar to pure conductive materials of high precision, accredited laboratory conditions, showing linearity.

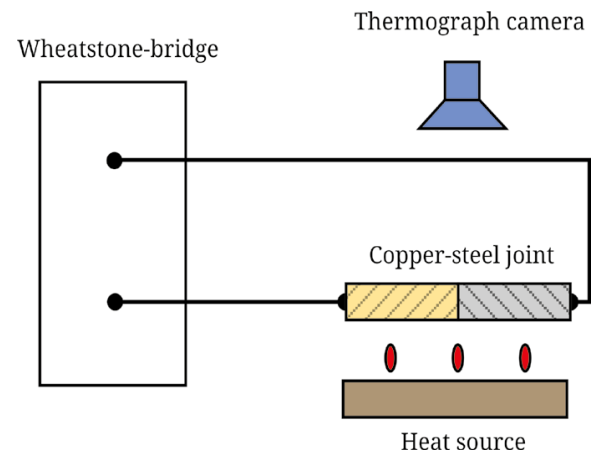

Figure 5. Schematic diagram of the measurement

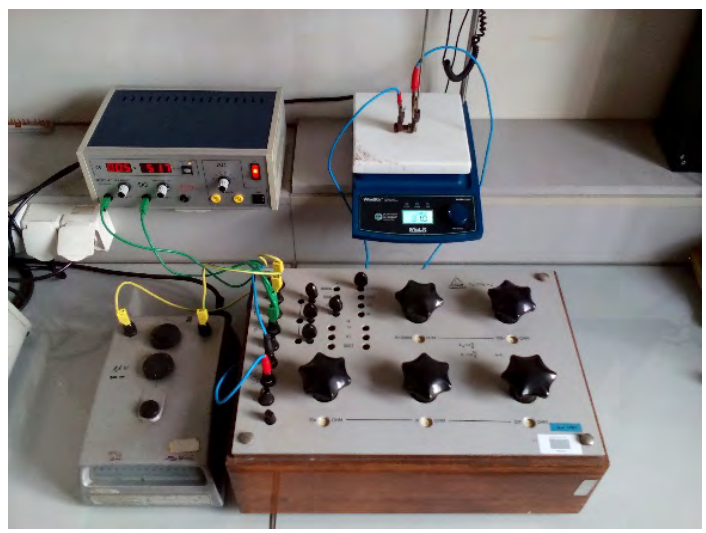

Figure 6. Setup of the measurement

Table 1. Measured values

\begin{tabular}{|c|c|c|}
\hline Number & $\begin{array}{c}\text { Temperature } \\
\mathbf{C}^{\circ}\end{array}$ & $\begin{array}{c}\text { Resistance } \\
\boldsymbol{\Omega}\end{array}$ \\
\hline 1. & 254 & 0.1 \\
\hline 2. & 309 & 0.2 \\
\hline 3. & 360 & 0.3 \\
\hline 4. & 410 & 0.4 \\
\hline 5. & 460 & 0.5 \\
\hline 6. & 505 & 0.6 \\
\hline
\end{tabular}

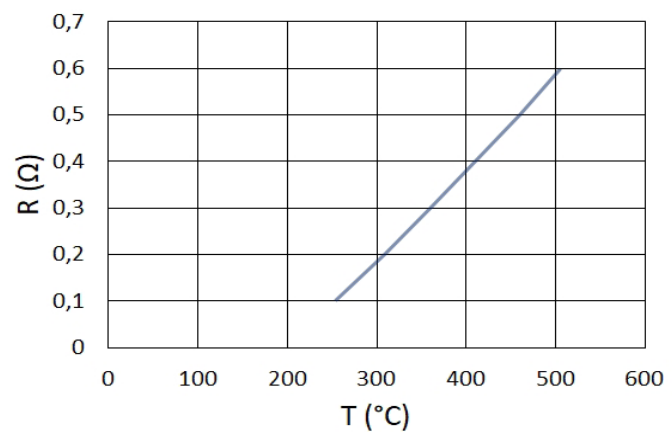

Figure 7. Resistance ratio temperature dependence

\section{Conclusions}

The aim of our study was to examine the resistance of the current-conducting components used by the electrical industry as a function of temperature. Is it different and, if so, how much does it deviate from the literature values? The difficulty of the measurements and the accuracy of the evaluation were given by the differences in production, given that a multimember assembly was the subject of the test. Comparing the temperature factors for each material found in the literature with the copper-steel component we find the following:

The copper and steel temperature coefficient varies between $\alpha_{20}=3,92 \cdot 10^{-3}$ and $4,2 \cdot 10^{-3}$. During our measurement, we have shown a multiple or even a magnitude increase of $250{ }^{\circ} \mathrm{C}$ to $500{ }^{\circ} \mathrm{C}$ (30 $\left.-40 \cdot 10^{-3}\right)$. EAt these temperatures, therefore, one piece of one Ohm resistive material changes its value by $1^{\circ} \mathrm{C}$. The resistance of the electric fittings exposed to the aforementioned contact corrosion is therefore not only increased by the increase of the transition resistance. We must also account for the increase in the resistance of the material in this way, especially if it is necessary to accurately keep the temperature characteristics of a component: according to the results of this paper, depending on the current, several different $10{ }^{\circ} \mathrm{C}$ differences may occur. Other factors influencing the resistance may also include mechanical (pressure and stretching) of electrical components.

\section{References}

[1] Haraszti F. : The bases of corrosion's investigation. In: Proceedings of the $21^{\text {th }}$ international scientific conference of youngth engineers, Cluj-Napoca, Romania, Müszaki Tudományos Közlemények 5. (2016) 185-188. https://eda.eme.ro/handle/10598/29058

[2] Haraszti F.: Corrosion investigation of steel samples. In: Proceedings of the $21^{\text {th }}$ international sci- 
entific conference of youngth engineers, Cluj-Napoca, Romania, Műszaki Tudományos Közlemények 5. (2016) 189-192.

https://eda.eme.ro/handle/10598/29057

[3] Kovács-C. T., Völgyi B., Sikari-Nágl I.: Galvanic corrosion behaviour testing in case of aluminium and steel couple. In: Fiatal műszakiak tudományos ülésszaka XVIII., Cluj-Napoca, Romania, Műszaki Tudományos Füzetek 2013. 201-204. https://eda.eme.ro/handle/10598/26880

[4] Kovács-C. T., Völgyi B., Sikari-Nágl I.: Investigation of aluminium-steel joint formed by explosion welding. Journal of Physics - Conference Series 602. (2015) 1-4. https://doi.org/10.1088/1742-6596/602/1/012026

[5] Wu Y., Barton S. C., Lee A.: Galvanic corrosion behavior at the $\mathrm{Cu}-\mathrm{Al}$ ball bond interface: Influence of $P d$ addition and chloride concentration. Microelectronics Reliability, 92. (2019) 79-86. https://doi.org/10.1016/j.microrel.2018.11.016

[6] Hack H. P.: Galvanic Corrosion. Reference Module in Materials Science and Materials Engineering, 2016. https://doi.org/10.1016/B978-0-12-803581-8.01594-0

[7] Hakansson E., Hoffman J., Predecki P., Kumosa M.: The role of corrosion product deposition in galva- nic corrosion of aluminum/carbon systems. Corrosion Science, 114. (2017) 10-16.

https://doi.org/10.1016/j.corsci.2016.10.011

[8] Khadom A. A., Abod B. M.: Mathematical model for galvanic corrosion of steel-copper couple in petroleum waste in presence of friendly corrosion inhibitor. Journal of Applied Research and Technology, 15. (2017) 14-20.

https://doi.org/10.1016/j.jart.2016.10.004

[9] Wellons M.: The Stefan-Boltzmann Law. Physics Department, College of Wooster, Wooster, Ohio 44691, USA, May 9, 2007.

http://g.wooster.edu/JrIS/Files/Wellons_Web_Article.pdf

[10] Dománková M., Kocsisová E., Slatkovský I., Pinke P.: The Microstructure Evolution and Its Effect on Corrosion Properties of $18 \mathrm{Cr}-12 \mathrm{Ni}-2,5 \mathrm{Mo}$ Steel Annealed at $500-900^{\circ} \mathrm{C}$. Acta Polytechnica Hungarica, 11/3. (2014) 125-137.

https://www.doi.org/10.12700/APH.11.03.2014.03.8

[11] Kittel C., Kroemer H.: Thermal Physics ASTM Standard Practice in A 262 for Detecting Susceptibility to Intergranular Corrosion in Austenitic Stainless Steels. W. H. Freeman and Company, 1980.

[12] Budó Á.: Kísérleti Fizika II. Tankönyvkiadó, Budapest, 1971. 